\title{
College Students' Sleep Habits and Their Perceptions Regarding Its Effects on Quality of Life
}

\author{
Megan L. Herrmann ${ }^{1}$, Anthena K. Palmer ${ }^{2}$, Morgan F. Sechrist ${ }^{3} \&$ Sam Abraham ${ }^{4}$ \\ ${ }^{1}$ Easter Seals Arc of Northeast Indiana, Fort Wayne, Indiana, USA \\ ${ }^{2}$ Saint Joseph Regional Medical Center, Cardiothoracic Surgery, Mishawaka, Indiana, USA \\ ${ }^{3}$ Case Manager/Admission Nurse, The Medical Team Hospice, Livonia, Michigan, USA \\ ${ }^{4}$ Associate Professor of Nursing, Bethel College, Mishawaka, Indiana, USA \\ Correspondence: Dr. Sam Abraham, Associate Professor of Nursing, Bethel College School of Nursing, 1001 \\ Bethel Circle, Mishawaka, Indiana, 46545, USA.
}

Received: January 10, 2018

doi:10.20849/ijsn.v3i2.297
Accepted: January 26, 2018

Online Published: January 29, 2018

URL: https://doi.org/10.20849/ijsn.v3i2.297

\begin{abstract}
Objective: Poor sleep in college students can attribute to poor academic performance. Poor sleep is detrimental to health; however, adequate sleep is not often seen as a priority. The objective of the study was to better understand college students' sleep habits and determine their perceptions regarding the effects of these sleep habits on quality of life.

Methodology: A quantitative, cross-sectional approach with a descriptive design was appropriate for this study. Participants were 122 students, in a Christian college with a population of about 2000 in the mid-western region of the United States. The survey instrument was developed with 6 demographic items and 19 statements using a 4-point Likert-type scale. Data collection occurred in the hallway of the library on two days in the spring semester of 2016.

Results: Regarding sleep habits, the average college student keeps their sleep and study spaces separate, they wake up at a regular time every day, they do use technology, such as a cell phone, TV/radio, computer, or iPad before going to sleep, and they have a sleep environment that is quiet and calming. A significant finding was that students did not think extracurricular activities (anything outside of class) negatively affected their sleep.

Conclusions: A large percentage of students use technology before bed, which places them at a higher risk for negative quality of life. Students admit to experiencing irregularity in their sleep patterns $(\mathrm{M}=3.59$, on a 4-point scale); however, most participants did not agree that caffeine consumption $(\mathrm{M}=2.15)$, extracurricular activities $(\mathrm{M}=2.25)$, or daytime naps $(\mathrm{M}=2.16)$ contributed to sleep problems.
\end{abstract}

Keywords: sleep and college students, sleep hygiene, sleep effects on health, napping and nighttime sleep, and sleep behaviors

\section{Introduction}

College students do not get the recommended number of hours of sleep each night. Vargas, Flores, and Robles (2014) stated that "college students experience frequent and sometimes severe sleep problems that negatively impact their health and well-being" (p. 534). Hirshkowitz et al. (2015) identified that young adults ages 18-25 years and adults 26-64 years should get 7 to 9 hours of sleep each night (p. 41). "The National Sleep Foundation reports insufficient sleep can be damaging and even life-threatening" (Orzech et al., 2011, p. 612). Sleep is a challenge for students and poor sleep can be linked to mental health issues and a person's academic performance (Orzech et al., 2011, p. 618). The purpose of the study was to better understand college students' sleep habits and determine their perceptions regarding the effects of these sleep habits on quality of life.

\section{Research Questions}

Two research questions used were: (1) What are the sleeping habits of college students? (2) What are college students' perceptions about the effect of their sleep habits on their quality of life?

\section{Background and the Literature Review}

College students are not known to have regular sleep patterns (Orzech, Salafsky, \& Hamilton, 2011). Orzech et al. (2011) found that " $25 \%-50 \%$ of college students report significant levels of daytime sleepiness, which may 
interfere with the performance of daily tasks such as driving and academics" (p. 612). Along with daytime sleepiness, students' lack of sleep can have negative effects on their physical and mental health, such as feeling more tense, irritable, depressed, and anxious (Orzech et al., 2011). Students acknowledged their poor sleep quality, but attributed their inattentiveness level the following day to be because of something other than sleep. There was disconnect between students' understanding of the effects of sleep and how they perceive sleep to affect their lifestyle and daily activities (Orzech et al., 2011).

Sleep pattern is also influenced by factors other than sleep hygiene. These factors are internal and external, environmental, physiological, and psychological; all of which are contributing factors to a person's sleep duration and quality (Teixeira et al., 2012). Sleep is an important aspect to maintaining a well-balanced lifestyle and living a healthy life physically, mentally, emotionally, and spiritually. Students need to be more aware of how sleep affects their lifestyle.

Ye, Johnson, Keane, Manasia, and Gregas (2015) found that periods of disturbed sleep or lack of sleep were caused by daytime napping. Students, who frequently took longer daytime naps, had decreased drive and attitude. Poorer nighttime sleep quality leads to poorer functioning and lower life satisfaction (Goldstein \& Walker, 2014; Ye et al., 2015).

Hershner and Chervin found, "at least 3 times a week $60 \%$ of students report that they are dragging, tired, or sleepy" (p. 73). The most common reason for sleepiness during the day in college students was related to not sleeping enough at night. "Good sleep hygiene includes a regular sleep-wake schedule, quiet sleep environment, and avoidance of caffeine after lunch, and stimulating activities before bed" (Hershner \&Chervin, 2014, p. 76). Hershner and Chervin also stated that minimal napping could increase alertness and productivity. Education, including proper sleep hygiene practices and sleep awareness, can decrease students' level of sleepiness.

Kloss, Nash, Walsh, Culnan, Horsey, and Sexton-Radek (2015) found that "nearly $70 \%$ of college students report sleep problems" (p. 1). It was found that "emotions, physical well-being, and cognition could be negatively impacted by a lack of sleep" (Kloss et al., 2015, p. 1). Voinescu and Szentagotai-Tatar (2015) identified that young adults had a lower awareness of sleep hygiene compared to their adult and middle-aged adult counterparts.

Owens (2014) explained that the more sleep diminishing activities that were performed before bed, the poorer quality of sleep. These activities included using electronics in bed and caffeine consumption. A lack of needed sleep in adolescents caused mood disturbances, increased risk for obesity, drowsy driving, and suicidal ideation (Owens, 2014).

Vargas et al. (2014) identified a possible relationship between sleep and body mass index (BMI). "Over 30\% of the participants had a BMI > 25" and "51\% of the participants experiencing poor sleep quality" (Vargas et al., 2014 , p. 536). With this relationship between BMI and sleep quality, the relationship was identified and puts those who don't receive adequate sleep at a greater risk of developing future health complications (Vargas et al., 2014). It is important that students are made aware of the effects that sleep can have on their general health, including the risk for becoming overweight.

Knowlden and Sharman (2014) reported, "Individuals with inadequate sleep are more likely to report absenteeism, unintentional sleep during work hours, as well as work-related accidents" (p. 271). Along with performance at work and in everyday activities, students' sleep can have a negative result mentally and emotionally. "Sleep restriction increases human error rate, diminishes drive and motivation, and curtails emotional coping and stress-managing capacities" (Knowlden \& Sharman, 2014, p. 271). For employed students, Knowlden and Sharman (2014) suggested that stress related to multiple responsibilities restricted them from receiving the appropriate amount of sleep at night. Melton, Bigham, Bland, Bird, \& Fairman (2014) found that "the presence of media devices in the bedroom has been associated with a delayed bedtime and a significant loss in sleep" (Melton et al., 2014, p. 511). A decrease in the use of technology had the capability to help improve sleep habits (Melton et al., 2014, p. 516).

The demands of academic performance can add high levels of stress and sleep deprivation in students. Insufficient sleep can produce negative effects (Hirshkowitz et al., 2015) poor academic performance (Orzech et al., 2011); produce daytime sleepiness, and irritableness, (Orzech et al., 2011). Good sleep hygiene (Hershner \& Chervin, 2014) such as a routine schedule, restriction of caffeine and the effects of napping are identified. The relationship of sleeplessness to weight (Vargas et al., 2014) and the use of technology in bed (Melton et al., 2014) are also discussed. This data identified a need to investigate the college students sleeping habits and perceptions to identify if further intervention is needed.

\section{Methodology}

This was a quantitative, cross-sectional study with a descriptive design. A sample size of 122 students participated in a population of about 2000 students in a Christian college. The convenience sample allowed the 
study to account for a variety of ages, ethnicities, and academic years. Participants were all 18 years of age or older and were given the choice to participate in the study. The survey instrument was developed after a thorough review of literature. To obtain face-validity, the demographics and the 19 Likert-type survey statements were reviewed by peers and nursing faculty. Statements 1-9 addressed the participants sleep habits and they were measured by a 4-point frequency scale of never (1) to always (4). Statements 10-19 addressed the perceptions of how their sleep affects health and they were measured by a 4-point agreement scale of strongly disagree (1) to strongly agree (4). The proposal was approved by the Institutional Review Board (IRB).

The librarian was contacted and permission was received to collect data outside the library. The surveys were conducted in the hallway outside of the library over a two-day span during the afternoon hours between lunch and dinner. Miniature candy bars were provided as an incentive to complete the survey and draw attention to the survey table. The necessary tools were available: informed consent forms, surveys, pens, and two manila envelopes used for collecting the forms. Participants were given instruction as to how to complete the survey upon coming to the table. Participants were also instructed to sign the informed consent; a second copy of the informed consent was given to them. To maintain participant confidentiality, the completed informed consent and the survey were placed in separate manila envelopes labeled as such.

\section{Results}

Data analysis began after surveys were completed. Incomplete surveys were discarded. Percentages and frequencies were calculated for the demographic data (see Table 1). Among the 122 surveys that met criteria, 57\% were female and $93 \%$ were between the ages of 18-23. The participants had an approximately even distribution among the classification from freshmen to seniors. Sixty-five percent claimed to sleep 7-8 hours per night. Thirty-six percent never took naps during the day. With regards to napping during the week, most of the participants surveyed took between 0-2 naps a week. Approximately half of those participants did not take any naps during the week.

\subsection{Demographic Characteristics}

Table 1. Demographics

\begin{tabular}{|c|c|c|}
\hline Variable & $f$ & $\%$ \\
\hline \multicolumn{3}{|l|}{ Gender } \\
\hline Male & 52 & 43 \\
\hline Female & 70 & 57 \\
\hline \multicolumn{3}{|l|}{ Age range } \\
\hline $18-20$ & 53 & 43 \\
\hline $21-23$ & 61 & 50 \\
\hline $24-26$ & 1 & 1 \\
\hline $27 \geq$ & 7 & 6 \\
\hline \multicolumn{3}{|c|}{ Year in school } \\
\hline Freshman & 25 & 20 \\
\hline Sophomore & 30 & 25 \\
\hline Junior & 34 & 28 \\
\hline Senior & 31 & 25 \\
\hline Other & 2 & 2 \\
\hline \multicolumn{3}{|c|}{ Number of people in household } \\
\hline 1 & 9 & 7 \\
\hline $2-3$ & 38 & 31 \\
\hline $4-5$ & 59 & 49 \\
\hline $6 \geq$ & 16 & 13 \\
\hline \multicolumn{3}{|c|}{ Average number of hours of sleep per night } \\
\hline$\leq 4$ & 1 & 1 \\
\hline $5-6$ & 40 & 33 \\
\hline $7-8$ & 79 & 65 \\
\hline $9 \geq$ & 2 & 1 \\
\hline \multicolumn{3}{|c|}{ Average number of naps each week } \\
\hline 0 & 43 & 36 \\
\hline $1-2$ & 56 & 46 \\
\hline $3-4$ & 16 & 13 \\
\hline $5 \geq$ & 6 & 5 \\
\hline
\end{tabular}

Note. $(N=122)$ 


\subsection{Sleeping Habits}

Data regarding sleeping habits in college students displayed in Table 2 categorizes the mean and standard deviation. "My sleep environment is calm and quiet" was the statement that received the highest mean of $(\mathrm{M}=3.16 ; \mathrm{SD}=0.76)$. The second highest mean was $3.04(\mathrm{SD}=0.97)$, which indicates that the participants use a form of technology prior to falling asleep. The following two statements, "Wake up at a consistent time" and "sleep and study spaces are separate" had about the same mean with the first having a mean of $2.83(\mathrm{SD}=1.03)$ and the latter mean of $2.74(\mathrm{SD}=0.81)$. These four statements indicate that the average college student keeps their sleep and study spaces separate, they wake up at a regular time every day, they do use technology before going to sleep, and they have a sleep environment that is quiet and calming.

Table 2. Sleeping habits of college students

\begin{tabular}{lll}
\hline Variable & $M$ & $S D$ \\
\hline My sleep environment is calm and quiet & 3.16 & 0.76 \\
I use technology in bed prior to falling asleep & 3.04 & 0.97 \\
(e.g. cell phone, TV/radio, computer, iPad) & & \\
I wake up at a consistent time in the morning & 2.83 & 0.79 \\
Sleep and study spaces are separate & 2.80 & 1.03 \\
I have a consistent bedtime routine & 2.74 & 0.81 \\
I go to sleep at a consistent time at night & 2.57 & 0.79 \\
It takes me more than 30 minutes to fall asleep & 2.46 & 0.89 \\
I am awake for more than 30 minutes during the night & 1.93 & 0.79 \\
I use natural aids to help me sleep. (e.g. teas or melatonin) & 1.41 & 0.71 \\
I use medication (prescription or OTC) to help me sleep & 1.16 & 0.55 \\
\hline
\end{tabular}

Note. $(N=122)$. Items were rated on a 4-point Likert-type scale ranging from 1 (Never) to 4 (Always), so higher means indicate higher levels of frequency.

\subsection{Health Perceptions}

In Table 3, statements regarding college students' perceptions regarding sleep habits are displayed. The statement, "college students experience sleep irregularities," had the highest mean of 3.59 ( $\mathrm{SD}=0.57)$. The next highest mean was 3.36 ( $\mathrm{SD}=0.64)$, which correlated with the statement, "good sleep quality, better concentration." Two statements that had about the same mean, both dealt with the negative effects of a lack of sleep. The first statement, "less sleep, more irritable," had a mean of $3.10(\mathrm{SD}=0.77)$. The second statement, "poor sleep increases risk of getting sick," had a mean of $3.06(\mathrm{SD}=0.75)$. Based on the higher means, the students agree their sleep pattern tends to be irregular, they concentrate better when they receive adequate sleep, and that a lack of sleep causes irritability and an increased risk of getting sick.

Table 3. College students' perceptions about the effect of their sleep habits on their health

\begin{tabular}{lll}
\hline Variable & $M$ & $S D$ \\
\hline College students experience irregularity in their sleep patterns. & 3.59 & 0.57 \\
I can concentrate better if I have good quality sleep the previous night. & 3.36 & 0.64 \\
The less sleep I get, the more irritable I am. & 3.10 & 0.77 \\
Poor quality sleep increases my risk for getting sick. & 3.06 & 0.75 \\
The more sleep I get, the brighter my mood is the next day. & 3.02 & 0.78 \\
The more sleep I get, the more physically active I am. & 2.88 & 0.66 \\
My sleep habits leave me feeling tired the next day. & 2.64 & 0.75 \\
My extracurricular activities (anything outside of class) negatively affect & 2.25 & 0.83 \\
my sleep. & & \\
Daytime naps greater than 30 minutes negatively affect my health. & 2.16 & 0.79 \\
My caffeine consumption affects my quality of sleep negatively. & 2.15 & 0.92 \\
\hline
\end{tabular}

Note. $(N=122)$. Items were rated on a 4-point Likert-type scale ranging from 1 (Strongly Disagree) to 4 (Strongly Agree), so higher means indicate higher levels of agreement. 


\section{Discussion}

In the current study, $64 \%$ of student participants agreed that they take from 1 to more than 5 naps per week. Prior study indicates students who frequently took longer naps, had decreased drive and attitude (Yet et al, 2015, p. 94). The students in this study agreed that whenever they received less sleep they were more irritable and it affected their concentration the following day. From the literature review and the results of the current study, a relationship is revealed that adequate sleep at night is beneficial for the person than little sleep at night and napping during the day. Only $66 \%$ agreed that they received seven or more hours of sleep per night. This could be a problem for the $34 \%$, who are not getting adequate sleep. It is possible that they are the one's taking naps during the day; however, frequent nappers tend to possess less drive (Yet et al, 2015). For the statement, "Daytime naps greater than 30 minutes negatively affect my health," the participants, contrary to research findings, scored one of the lowest means 2.16. This indicates either a need for more education regarding daytime naps or further research in this area. Educational programs, schedule changes, and minimal napping can provide interventions for sleepiness (Hershner \& Chervin, 2014).

The sleeping habit identified with the highest mean was; "My sleep environment is calm and quiet." Even though $93 \%$ of students claimed that, the number in their household was from 2 to more than 6 , maintaining a calm and quiet environment did not seem to be a problem. This finding supports prior research regarding the need for a quiet sleep environment to obtain rested sleep (Hershner \& Chervin, 2014).

Engaging in the use of technology was found to have the second highest mean (3.16) and was also referred to as something that students often do before falling asleep. The statement, "I use technology, such as cell phone, $\mathrm{TV} /$ radio, computer, iPad, in bed prior to falling asleep, received a mean of 3.04 on a 4-point scale. Unfortunately, literature findings indicate, engaging in technology activity is hindering on one's sleep. "The presence of media devices in the bedroom has been associated with a delayed bedtime and a significant loss in sleep" (Melton et al 2014, p. 511). With the multitude of media use by students, more research in this area is necessary to determine how it affects sleep, learning, and health. Sleep loss is not the only variable that is affected as a result of using technology. Lack of sleep can increase risk for obesity, driving while drowsy, and potential suicidal ideation (Owens, 2014). These results, though unfortunate, display the number of students that use technology before bed, which then places those students at a higher risk for negative effects.

Regardless of the extensive use of technology before bed, a significant number of participants claimed they wake up at a consistent time in the morning. They also asserted their sleep and study spaces are separate, they have a consistent bedtime routine, and that they go to bed at a consistent time. Hershner and Chervin (2014) identified good sleep hygiene includes regular sleep-wake schedule. Very few students claimed to use natural aids, over-the-counter, or prescription medications for sleep. If the sleep and study spaces are separate, it can be assumed that technology use during bedtime is not for study purpose.

In discussing perceptions, the participants agreed that they had irregularities in their sleep pattern $(M=3.59)$. It is important that they are able to acknowledge sleep irregularities, but it is also important to create a goal or plan to create a rather consistent sleep schedule to benefit their health. As Kloss et al. (2015) mentioned, "emotions, physical well-being, and cognition could be negatively impacted by a lack of sleep" (p. 1). Ye et al. (2015), discovered that "sleep deprivation and irregular sleep schedules, can lead to significant emotional imbalance, fatigue, poor concentration, impaired memory, and generally lower life satisfaction" (p. 88).

Students who participated in this study overwhelmingly agreed that they became more irritable, cannot concentrate better, became moody, felt tired, and the risk of getting sick was higher with lack of sleep. These findings support prior research stating, "Sleep restriction increases human error rate, diminishes drive and motivation, and curtails emotional coping and stress-managing capacities" (Knowlden \& Sharman, 2014, p. 271).

A significant finding was that students did not think extracurricular activities (anything outside of class) negatively affected their sleep. It can be argued that students may consider extracurricular activities as fun and socially enriching that they could be in denial this is affecting their sleep. More research on this topic is required. Another interesting finding was that students' perception of caffeine effects on sleep differed from what was found in the literature. The participants' overwhelmingly disagreed that caffeine negatively affected their sleep habits. On the contrary, researchers have discovered that the opposite is true. Owen (2014) explained sleep-diminishing activities that would contribute to poorer sleep quality was caffeine consumption. Hershner and Chervin (2014) also claimed that good sleep hygiene includes avoidance of caffeine after lunch (p. 76). More research in the area of caffeine use and its effects on college students will be useful. 


\section{Limitations}

A newly developed survey, even though face-validity was obtained, could be a limitation. External validity or generalizability of study results is a limitation because only one Christian college was surveyed. The sample size of 122 in a population of 2000 students may be a limitation.

\section{Implications and Recommendations}

College students are generally thought to receive less sleep than the recommended hours and this study can help validate this perception. This study identified $35 \%$ of the participants as receiving 6 or less hours of sleep per night. Students should be conscious and proactive when creating regular sleep habits. These habits should aid in creating a calm sleep environment and one that assists in receiving adequate sleep. Education regarding technology use before or while in bed should be discussed and available for students. Education regarding positive sleep habits, factors influencing sleep, and the influence that sleep has on health would also be of benefit to the student population. Promotion of college schedules and activities that encourage adequate sleep could have an impact on the quality of student life. Further research into the effects that sleep has on specific areas such as daytime naps, the use of technology, and the use of caffeine would be beneficial.

\section{Conclusion}

The purpose of the study was to better understand college students' sleep habits and determine their perceptions regarding the effects of these sleep habits on quality of life. The results indicated majority of students agreed to having a calm and quiet sleep environment. The high number of students using technology before bed was identified as an area of concern. Perceptions of the ways students believed their sleep affected their quality of life included having irregular sleep patterns. It was also identified that students realized adequate sleep was beneficial while a lack of sleep had negative consequences including irritability and less concentration. However, to conclude that poor sleep habits are the true cause of worsening quality of life or causing illness, irritability, or mood changes may be premature. More studies on this topic would be helpful. As students become aware and actively seek out ways to better their quality of life, they will be more mentally, emotionally, and spiritually healthy. This study helped identify that college students have an understanding of some aspects of healthy sleep habits and the link between sleep habits and quality of life. Again, education on the effects of sleep on the quality of life would be of benefit to the college community.

\section{Acknowledgment}

The authors wish to acknowledge Dr. Deborah Gillum, Dean of the School of Nursing, Bethel College, Indiana, for offering valuable comments during the early stages of the study. We also like to thank Bethel College administrators for giving us the opportunity to conduct this study.

\section{References}

Goldstein, A. N., \& Walker, M. P. (2014). The role of sleep in emotional brain function. Annu Rev Clin Psuchol, 10, 679-708. https://doi.org/10.1146/annurev-clinpsy-032813-153716

Hershner, S., \& Chervin, R. (2014). Causes and consequences of sleepiness among college students. Nature and Science of Sleep, 6, 73-84. https://doi.org/10.2147/NSS.S62907

Hirshkowitz, M., Whiton, K., Albert, S. M., Alessi, C., Bruni, O., Doncarlos, L., . . Adams Hillard, P. J. (2015). National Sleep Foundation's sleep time duration recommendations: Methodology and results summary. Sleep Health, 40-43. https://doi.org/10.1016/j.sleh.2014.12.010

Kloss, J. D., Nash, C. O., Walsh, C. M., Culnan, E., Horsey, S., \& Sexton-Radek, K., (2015). A "sleep 101" program for college students improves sleep hygiene knowledge and reduces maladaptive beliefs about sleep. Behavioral Medicine, 1-9. https://doi.org/10.1080/08964289.2014.969186

Knowlden, A. P., \& Sharman, M. (2014). Health belief structural equation model predicting sleep behavior of employed college students. Family and Community Health, 37(4), 271-278. https://doi.org/10.1097/FCH.0000000000000043

Melton, B., Bigham, L., Bland, H., Bird, M., \& Fairman, C. (2014). Health-related behaviors and technology usage among college students. American Journal of Health Behavior, 38(4), 510-518. https://doi.org/10.5993/AJHB.38.4.4

Orzech, K. M., Salafsky, D. B., \& Hamilton, L. A. (2011). The state of sleep among college students at a large public university. Journal of American College Health, 59(7), 612-619. https://doi.org/10.1080/07448481.2010.520051 
Owens, J. (2014). Insufficient sleep in adolescents and young adults: An update on causes and consequences. American Academy of Pediatrics, 134(3), 921-932. https://doi.org/10.1542/peds.2014-1696

Teixeira, T., Lowden, A., Aparecida da Luz, A., Lemos Turte, S., Valente, D., Jun Matsumura, R., . . . Pickersgill de Paula, L. (2012). Sleep patterns and sleepiness of working college students. WORK: $A$ Journal of Prevention, Assessment, \& Rehabilitation, 41, 5550-5552. https://doi.org/10.3233/WOR-2012-0879-5550

Vargas, P. A., Flores, M., \& Robles, E. (2015). Sleep quality and body mass index in college students: The role of sleep disturbances. Journal of American College Health, 62(8), 534-541. https://doi.org/10.1080/07448481.2014.933344

Voinescu, B., \& Szentagotai-Tatar, A. (2015). Sleep hygiene awareness: Its relation to sleep quality and diurnal preference. Journal of Molecular Psychiatry, 3(1), 1-7. https://doi.org/10.1186/s40303-015-0008-2

Ye, L., Johnson, S. H., Keane, K., Manasia, M., \& Gregas, M. (2015). Napping in college students and its relationship with nighttime sleep. Journal of American College Health, 63(2), 88-97. https://doi.org/10.1080/07448481. 2014. 983926

\section{Copyrights}

Copyright for this article is retained by the author(s), with first publication rights granted to the journal.

This is an open-access article distributed under the terms and conditions of the Creative Commons Attribution license (http://creativecommons.org/licenses/by/4.0/). 